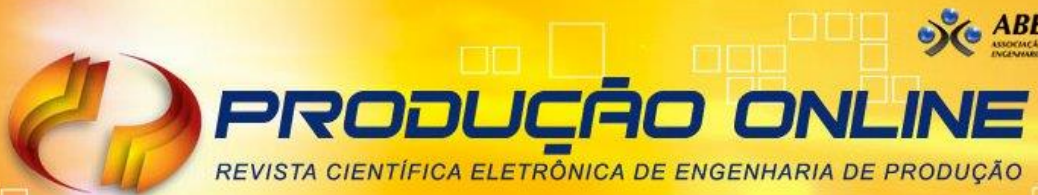 ISSN 1676-1901
}

\section{APLICAÇÃO DO MÉTODO INTITULADO DINÂMICA DA COZINHA EM AULA DE GESTÃO DA PRODUÇÃO}

\section{APPLICATION OF THE METHOD TITLED KITCHEN DYNAMIC IN PRODUCTION MANAGEMENT CLASSROOM}

\author{
Antonio Wagner Forti* E-mail: aw.forti@unesp.br \\ Jorge Muniz Junior* E-mail: jorge86056@gmail.com \\ *Universidade Estadual Paulista (UNESP), Faculdade de Engenharia, Guaratinguetá.
}

\begin{abstract}
Resumo Os egressos dos cursos de Engenharia, de acordo com a visão dos estudantes de Engenharia e a Resolução do Conselho Nacional de Educação do Ministério da Educação do Brasil (CNE/CES 11, de 11 de Março de 2002), devem possuir determinadas habilidades e competências, entre elas boa comunicação, organização de ideias, visão crítica, autodidatismo e saber trabalhar em equipe, as quais são fundamentais para o exercício da profissão. Apesar disso, algumas delas não são estimuladas no decorrer de determinados cursos de Engenharia. Pensando nisso, esse trabalho apresenta uma dinâmica, denominada de Dinâmica da Cozinha, a qual estimula os estudantes a tomar decisão; trabalhar, discutir e negociar com outros estudantes e analisar dados fornecidos, ou seja, que eles exercitem habilidades e competências necessárias ao Engenheiro. A Dinâmica da Cozinha é baseada em grupos de trabalho, os quais devem definir um cardápio de restaurante industrial com prato principal, sopa, salada, guarnição, sobremesa e suco. Na primeira etapa da dinâmica, cada grupo recebe uma informação sobre os itens disponíveis (calorias, custos, aceitação e tempo e dificuldade dos pratos) para elaboração e apresentação do cardápio. No final dessa etapa cada grupo apresenta seu cardápio e discute-se a relação da Dinâmica da Cozinha com a realidade organizacional de empresas. $\mathrm{Na}$ segunda etapa os grupos são reorganizados de modo que, os novos grupos tenham pelo menos um estudante de cada grupo da primeira etapa. No final dessa etapa os grupos apresentam seus cardápios e ocorre a uma nova roda de discussões. Os resultados, obtidos através do feedback dos estudantes logo após a aplicação da Dinâmica da Cozinha, utilizando enfoque qualitativo, evidenciam que ela estimulou a participação, a reflexão e discussão crítica dos resultados, o que é importante para os estudantes desenvolverem habilidades e competências necessárias para os engenheiros.
\end{abstract}

Palavras-chave: Engenharia Simultânea. Ensino de Engenharia. Habilidades do Engenheiro. Tomada de Decisão. Engenharia Multidisciplinar.

\begin{abstract}
According to engineering students and the Resolution of the National Council of Education Ministry of Education from Brazil (CNE/CES 11 - March 11, 2002), the engineer, to practice engineering, must have skills and competences like: communication; clarity and conciseness; argumentative; selflearning; teamwork; decision making and analyse data among others. Despite this, some of them, are not stimulated during some engineering courses. As a propose to encourage the students to exercise some of them, this work presents a dynamic titled Kitchen Dynamic. This dynamics is based on work groups, which should propose an industrial restaurant menu with main course, soup, salad, garnish, dessert and juice. In the beginning of the first stage of the dynamic, the students of each group receive only one information about every available item (calories, costs, acceptance and time-difficulty to make it) for proposing and presenting their menu. After that the moderator clarifies the similarity between the Kitchen Dynamic and organizational structure of industry. Finally the moderator encourages the students to discuss about that. In the second stage of the dynamic, the groups are mixed, for that every new group have at least one student from every groups of first stage. At the end of this stage the groups present their menu and a new round of discussions takes place. The results, obtained by feedback from the students soon after the dynamic, showed that the Kitchen Dynamic stimulated their participation reflection and discussions of the results, what is important to the students develop skills and competences needed to engineers.
\end{abstract}


Keywords: Simultaneous Engineering. Engineering Teaching. Engineer Skills. Decision Making. Multidisciplinary Engineering.

\section{INTRODUÇÃO}

O presente artigo analisa a aplicação da Dinâmica da Cozinha, como estratégia de ensino com a finalidade de desenvolver competências e habilidades, presentes na Resolução CNE/CES de 11 de março de 2002 (MEC, 2002), em estudantes de engenharia. De acordo com essa resolução, cada curso de engenharia deve proporcionar aos estudantes atividades, as quais desenvolvam as competências e habilidades esperadas dos egressos.

A Dinâmica da Cozinha sugere uma prática de ensino-aprendizado que estimule o engajamento dos estudantes de engenharia, através da tomada de decisão, trabalho em equipe, análise de dados e negociação, as quais auxiliam no desenvolvimento de algumas competências e habilidades presentes na Resolução mencionada. A Dinâmica da Cozinha é baseada na competição entre grupos de estudantes, os quais recebem dados para definição de um cardápio de restaurante industrial, visando relacioná-lo com problemas organizacionais em empresas.

Existe uma preocupação generalizada quanto ao fortalecimento de competências e habilidades envolvendo conteúdos técnicos aos estudantes de Engenharia no decorrer de sua formação. Lujan e DiCarlo (2006) indicam que para a compreensão de conteúdos pelos estudantes deve-se reduzir a quantidade de informação factual e o formato passivo das aulas, bem como estimular o engajamento ativo do estudante, a autonomia e a aptidão de solucionar problemas.

As estratégias pedagógicas podem influenciar o desenvolvimento destas competências e habilidades nos estudantes. Por exemplo, estudantes de Humanidades e Ciências Sociais são mais estimulados à participação e reflexão durante as aulas em seus cursos do que os de Ciências Naturais e Engenharia, os quais são mais focados em aspectos técnicos e operacionais, ou seja, baseiam-se na reprodução do conhecimento (BRINT; CANTWELL; HANNEMAN, 2008).

O Ensino na área de Engenharia tem enfrentado desafios relativos ao desenvolvimento de habilidades e competências dos egressos que são valorizadas pelos empregadores e que, normalmente, não são estimuladas no decorrer da graduação (MUNIZ JR. et al., 2018; MESQUITA; LIMA; PEREIRA, 2008). Muniz Jr. et 
al. (2009) identificaram que os próprios estudantes de Engenharia valorizam competências e habilidades para o exercício profissional distintas dos conteúdos das disciplinas, entre elas trabalho em equipe, boa comunicação, organização de ideias, visão crítica e autodidatismo. Nessa perspectiva, procura-se responder ao seguinte problema da pesquisa: A Dinâmica da Cozinha pode contribuir para que os estudantes de Engenharia desenvolvam as competência e habilidades indicadas?

A abordagem metodológica desta pesquisa é qualitativa, e foi aplicada numa amostra de 100 graduandos dos cursos de Engenharia Mecânica Diurno e Noturno, numa Universidade pública do Estado de São Paulo, na disciplina de Gestão de Produção. A análise é baseada na percepção dos estudantes sobre a importância da Dinâmica e na indicação de seus pontos positivos, os quais visam estimular o desenvolvimento de competências e habilidades necessárias aos engenheiros.

Buscando responder ao referido problema, este artigo apresenta, na Seção 2, a fundamentação teórica sobre o Ensino na Engenharia. Na seção 3 é descrita a Dinâmica da Cozinha. Na Seção 4 é apresentado o procedimento de pesquisa. $\mathrm{Na}$ Seção 5 são discutidos os resultados alcançados e na Seção 6 é elaborada a conclusão do trabalho.

\section{FUNDAMENTAÇÃO TEÓRICA}

Lang et al. (1999) e Martin et al. (2005) relatam que transformações na Engenharia são em parte responsáveis pelo surgimento de questões associadas à educação de Engenheiros, tais como: capacidade para trabalhar em equipe, lidar com problemas complexos e interdisciplinares com grande volume de teorias, técnicas, normas e instrumentos. Embora tais transformações sejam reflexos do cotidiano, a economia e a vida em sociedade apresentam outros desafios, como a necessidade de trabalhar em rede, definir o tempo que deseja permanecer conectado a ela, ser adaptável a mudanças e saber definir e manter o foco de atuação em um ambiente altamente complexo.

Jackson, Meyer, Parkinson (2006) indicam que o calouro de curso superior pode ser visto como alguém que busca apropriar-se do modo de discursar de uma comunidade acadêmica (professores, funcionários e estudantes). Prevê-se que, durante a vida acadêmica, o estudante adquirirá competências técnicas e comportamentais necessárias para o exercício profissional. Como o ensino é 
estruturado a partir de uma ótica geral, que visa dar tratamento igual a todos que ingressam no sistema de ensino, o desenvolvimento dessas competências ocorre dentro de disciplinas curriculares e contextos educacionais e sociais que permeiam o ensino, sejam eles: centrados no professor e/ou no estudante; presencial e/ou a distância; aula expositiva e/ou fórum; solução de problemas; desenvolvimento de projetos e dinâmicas. Parte-se da premissa que o estudante se adapta à comunidade e aos estímulos a que ele está exposto.

Ellis et al. (2008) apresentam duas formas de aprendizado: a Profunda (Deep) na qual há orientação para compreensão, criação de sentido pessoal e aprendizado ativo e a Superficial (Surface) na qual há orientação para memorização e reprodução de conhecimento, algumas vezes acompanhado de engajamento pessoal e atividade de aprendizado. O Quadro 1 apresenta a relação das ideias acerca dos impactos das formas de aprendizado, a partir do trabalhos de Ellis et al. (2008) e Gibbs (1992, apud KEMBER, LEUNG e MCNAUGHT, 2008).

Quadro 1 - Impacto das formas de aprendizado

\begin{tabular}{|l|l|}
\hline Formas de Aprendizado & \multicolumn{1}{|c|}{ Impacto na Forma de Aprendizado } \\
\hline Profunda (Deep) & $\begin{array}{l}\text { a) Base de conhecimento bem estruturada. } \\
\text { b) Contexto motivacional apropriado. } \\
\text { c) Atividade de aprendizagem. } \\
\text { d) Interação entre os estudantes e o docente. }\end{array}$ \\
\hline Superficial (Surface) & $\begin{array}{l}\text { a) Elevada carga de trabalho. } \\
\text { b) Elevado número de horas de contato com a classe. } \\
\text { c) Excessiva quantidade de conteúdos. } \\
\text { d) Perda de oportunidade para explorar conteúdos em } \\
\text { profundidade. } \\
\text { e) Lacunas na escolha dos objetos de estudo e falha na } \\
\text { adoção de métodos de estudo. } \\
\text { f) Sistema de avaliação que provoca medo e ansiedade. }\end{array}$ \\
\hline
\end{tabular}

Fonte: Ellis et al. (2008) e Gibbs (1992) apud Kember, Leung e McNaught, 2008 (adaptado)

A abordagem superficial tende a manter o estudante focado na reprodução do conhecimento, nas notas de aprovação, nas avaliações tradicionais, enquanto que o professor transmite o maior conteúdo possível da disciplina para seus estudantes. Apesar do excesso de trabalho, da quantidade de tempo junto, o processo ensinoaprendizagem é tenso, cansativo e desgastante para ambos. O estudante 
sobrecarregado por memorização e o docente sobrecarregado por preparação de material e correção de avaliações.

Brint, Cantwell e Hanneman (2008, p. 398) discutem que a área do conhecimento influencia o processo ensino-aprendizagem e 0 engajamento acadêmico dos graduandos. As áreas de Ciências Sociais e Humanidades estimulam a interação e discussão e provoca os estudantes para que contribuam com novas ideias. Em contrapartida, as áreas de Ciências Naturais e Engenharia promovem estudo colaborativo e aprendizado das competências e habilidades técnicas. A comparação de culturas das duas áreas é apresentada no Quadro 2.

Quadro 2 - Cultura de engajamento dos estudantes por área

\begin{tabular}{|c|c|c|c|}
\hline ÁREA & $\begin{array}{l}\text { ENGAJAMENTO É } \\
\text { PROMOVIDO POR: }\end{array}$ & FRAQUEZAS & $\begin{array}{c}\text { FORMAS DE PROMOVER } \\
\text { ENGAJAMENTO }\end{array}$ \\
\hline $\begin{array}{l}\text { Ciências } \\
\text { Naturais e } \\
\text { Engenharia }\end{array}$ & $\begin{array}{l}\text { _ Compreensão baseada } \\
\text { na racionalidade. } \\
\text { quantitativa. } \\
\text { - Estudo colaborativo. } \\
\text { - Desempenho em } \\
\text { componente técnica. }\end{array}$ & $\begin{array}{l}\text { _ Recompensa pela } \\
\text { realização das atividades } \\
\text { requeridas (não pela } \\
\text { criatividade). } \\
\text { - Pouca iniciativa fora das } \\
\text { atividades requeridas. } \\
\text { - Pouco interesse na } \\
\text { conexão de ideias. } \\
\text { - Pouca interação entre } \\
\text { professores e estudante. }\end{array}$ & $\begin{array}{l}\text { _ Incentivar interação em } \\
\text { classe. } \\
\text { _ Promover atividades de } \\
\text { trabalho colaborativo. } \\
\text { _ Despertar o ânimo em } \\
\text { apresentações, debates } \\
\text { e discussões. } \\
\text { _ Encorajar a participação } \\
\text { em dinâmicas vivenciais. }\end{array}$ \\
\hline $\begin{array}{l}\text { Ciências } \\
\text { Sociais e } \\
\text { Humanidades }\end{array}$ & $\begin{array}{l}\text { _ compreensão baseada } \\
\text { na expressão e } \\
\text { interpretação. } \\
\text { _ interesse na ideia (maior } \\
\text { do que em sua } \\
\text { aplicação). } \\
\text { _ compartilhamento oral } \\
\text { sobre as interpretações } \\
\text { observadas num tema. } \\
\text { _ interação e discussão. }\end{array}$ & $\begin{array}{l}\text { Recompensar estudantes: } \\
\text { _ pela aptidão verbal } \\
\text { (menos pela profundidade } \\
\text { do estudo). } \\
\text { _ por fazer mais do que o } \\
\text { requerido por interesse } \\
\text { pelo assunto. }\end{array}$ & $\begin{array}{l}\text { Incentivar aprendizado } \\
\text { colaborativo. }\end{array}$ \\
\hline
\end{tabular}

Fonte: Brint, Cantwell, Hanneman (2008, p. 398)

O aprendizado deve ajudar o estudante a se tornar ativo, independente e apto a solucionar problemas. Uma maneira de contribuir para isso é analisar o formato das aulas. Na maioria das vezes predomina o monólogo do docente (LUJAN e DiCARLO, 2006), indicando a necessidade de se propor melhorias que possam torná-las mais eficientes e eficazes. Os currículos da Engenharia se alteraram pouco quanto ao conteúdo no decorrer dos anos (DYM, 2004), em essência houve a inclusão de conteúdos sobre novas tecnologias. A formação conteudista tradicional não desenvolve habilidades de comunicação e ética profissional (LANG et al., 1999). 
Tipicamente no Brasil, o Engenheiro é formado em conjuntos de disciplinas, com aulas presenciais e discursivas. $O$ aprendizado ativo e a análise crítica da informação facilitam o aprendizado e aulas meramente expositivas, contudo não são suficientes para um aprendizado eficaz. As Provas do ENADE 2017, Exame Nacional de Avaliação do Estudante (ENADE, 2017), valorizam as Competências e Habilidade, e nesse ponto os cursos de Engenharia necessitam revisões didático-pedagógicas para desenvolvê-las nos estudantes. O estudante deve construir sua própria compreensão de conhecimentos, relacionamentos e procedimentos.

Educadores têm enfatizado a importância e a necessidade de "atividades de aprendizado autênticas" para estudantes de engenharia, nas quais eles possam trabalhar com problemas do mundo real (BROWN, COLLINS e DUGUID, 1989 apud HWANG e CHANG, 2011). Montero e González (2009) enfatizam que aprender envolve a construção do conhecimento, exigindo que o estudante procure, ativamente, criar significado para suas próprias experiências pela relação de novas informações com as que já dispunha. Ellis et al. (2008) indicam que os fatores relativos ao melhor desempenho de aprendizado em graduandos têm duas componentes:

- Estudantil: o que eles fazem e, o que e como eles pensam quando trabalham. A atividade do estudante está diretamente relacionada com os resultados do ponto de vista do aprendizado;

- Ambiental/ensino: que provêm das relações indiretas com resultados positivos relativos ao aprendizado.

Docentes podem encorajar o processo de aprendizado por meio de diferentes estratégias de ensino (LUJAN e DiCARLO, 2006). Uma estratégia que pode contribuir significativamente para a aprendizagem dos estudantes de engenharia é sua participação em dinâmicas vivenciais que os confrontem com problemas. O aprendizado vivencial tem papel importante ao contribuir para que o estudante desenvolva habilidades de expor ideias, falar em público, ser conciso e objetivo ao comunicar uma ideia, entender o que outras pessoas falam e aprender coletivamente.

O Comitê de Acreditação para Engenharia e Tecnologia (ABET) indica algumas habilidades importantes para os egressos, como: comunicação interpessoal, realização de apresentações individuais, escrita (técnica e não técnica), elaboração de estudos de casos (DYM, 2010, p. 50; MOHAN et al., 2009). Acrescentam-se ainda habilidades como: 
- Trabalhar em equipe, desenvolver pensamento criativo e consciência de autocrítica, comprometer com auto-aprendizado, sendo esse último considerado relevante para garantir o desenvolvimento intelectual ao longo da vida (MONTERO E GONZÁLEZ, 2009, p. 214);

- Ouvir, construir mensagens, tomar decisões, solucionar problema, liderança, perspectiva multidisciplinar, negociação, solução de conflitos, organizar metas, compreender diversidade e globalização (MOHAN et al., 2009).

Algumas pesquisas indicam que deve-se encorajar times colaborativos nos processos de ensino e de aprendizado em sala de aula (MARCH; GAFFNEY, 2010; DYM, 2004; LANG et al., 1999). A Pesquisa Nacional de Engajamento Estudantil (NSSE), conduzida por Brint, Cantwell, Hanneman (2008, p. 384), apresenta três aspectos que podem promover o engajamento dos estudantes no processo de aprendizado:

1. Aprendizado Colaborativo Ativo que tem foco em práticas que estimulem o estudante a se envolver mais em sua educação. Essas práticas incluem realizar questões e contribuir com a discussão em sala de aula, fazer apresentações, trabalhar com outros estudantes em projetos durante a aula, trabalhar com os colegas fora de sala, discutir ideias de leitura;

2. Promoção de experiências que permitam aos estudantes acompanhar como docentes especialistas solucionam problemas. Essas experiências incluem discutir atividades, falar sobre planos de carreiras, discutir ideias, receber feedback de desempenho com os docentes;

3. Competições acadêmicas baseadas nas experiências que promovem altos níveis de realização. Isto inclui tempo de preparação para aula, trabalhar para alcançar as expectativas dos professores, tarefas de leitura, escrita, cursos que enfatizam elaboração de relatórios, aplicação das teorias em problemas práticos.

O NSSE afirma que os benefícios promovidos por esses aspectos são: criação de um senso de comunidade de estudo; disciplina de estudo; autonomia do estudante; articulação de ideias próprias; possibilidade de aprender com o conteúdo criado coletivamente; elaboração de modelos por meio de perguntas e respostas; respeito à pesquisa e sua aplicação em situações reais (BRINT; CANTWELL; HANNEMAN, 2008, p. 384).

Revista Produção Online. Florianópolis, SC, v. 19, n. 4, p. 1304-1326, 2019 


\section{DINÂMICA DA COZINHA}

A Dinâmica da Cozinha foi desenvolvida por um dos autores e, é baseada em grupos de trabalho, os quais devem definir um cardápio de restaurante industrial com prato principal, sopa, salada, guarnição, sobremesa e suco. Ela explora conceitos de desenvolvimento de produto/serviço e estimula o desenvolvimento de competências e habilidades para engenheiros como: atuar em equipes; comunicar-se eficientemente; avaliar criticamente a operação de sistemas; resolver problemas. A aula da Dinâmica possui 3 (três) atividades:

a) Pré-aula com leitura de artigo sobre conceitos relacionados ao desenvolvimento de produtos/serviços, tais como: Quality Function Deployment (LIMA; MUNIZ Jr.; FORTI, 2012); Engenharia Simultânea (MUNIZ Jr., 2018); Método de tomada de decisão (GUIMARÃES E ÉVORA, 2004).

b) Dinâmica vivencial (Apêndice 1), na qual grupos de estudantes recebem dados específicos e distintos para orientar a definição de cardápio. Cada grupo recebe informações e restrições específicas e distintas referentes a cada item do cardápio relacionadas às áreas organizacionais, para tomar sua decisão sobre o melhor cardápio. Desse modo, o item calorias estaria relacionado à área de Engenharia; a preferência do cliente com a área da Qualidade; os custos dos pratos com a área de Finanças; e o tempo e grau de dificuldade com a Produção.

c) Apresentação e discussão dos principais resultados à luz dos conceitos estudados, destacando as competências e habilidades desenvolvidas para além do aprendizado do conteúdo, estimulando a análise crítica, elaboração de feedback e a autocrítica.

Palmer, Holt e Bray (2008, p. 851) defendem a valorização das atividades dentro da própria aula para estimular alto nível de participação e discussão, e indicam resistência de estudantes a atividades extraclasses.

A Dinâmica da Cozinha é detalhada no Apêndice 1 e ilustrada na Figura 1. Na primeira rodada da dinâmica cada grupo deverá elaborar um cardápio baseado na informação recebida e em critérios próprios. Cada grupo recebe uma informação diferente, contudo, na maioria das vezes, os participantes da dinâmica pensam dispor 
da mesma informação. Após a elaboração dos cardápios, cada grupo apresenta suas escolhas e descreve o critério de decisão aplicado, baseado nas informações recebidas. No final desta rodada, o professor deve explorar a relação da dinâmica com a realidade organizacional; por exemplo, definição de critérios para tomada de decisão, decisão baseada em fatos e dados, relação dos grupos com áreas organizacionais, domínio do tempo, entre outras.

$\mathrm{Na}$ segunda rodada os grupos são reorganizados de modo que cada grupo tenha pelo menos um integrante dos demais grupos da rodada anterior. Dessa maneira, cada grupo passa a dispor de informações mais amplas para elaborar um novo cardápio na ótica organizacional (Engenharia, Finanças, Qualidade e Produção). Assim sendo, nesta rodada, cada grupo novo deverá elaborar um cardápio, baseado num conjunto de informações mais amplo. Portanto, esses grupos devem rever os critérios e ponderar sobre a importância relativa de cada informação para a elaboração do novo cardápio. Ao final dessa rodada cada grupo apresenta seu cardápio e descreve os critérios utilizados para elaborá-lo.

Figura 1 - Etapas da Dinâmica
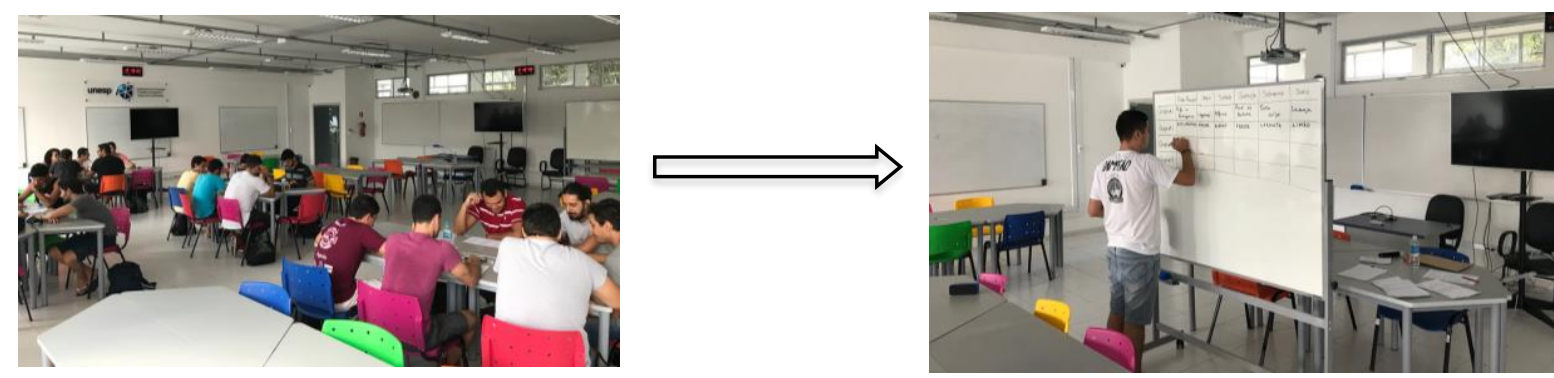

1ํㅡ Rodada - Cada grupo discute e elabora o cardápio com apenas uma das informações disponíveis.
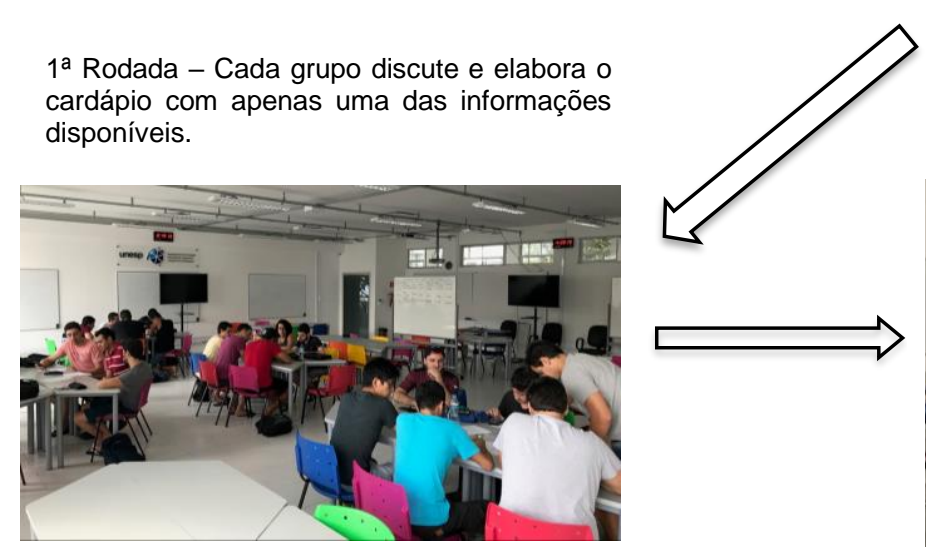

Cada grupo apresenta seu cardápio e informam aos demais grupos qual era a informação disponível para elaborá-lo. Há discussão dos resultados.

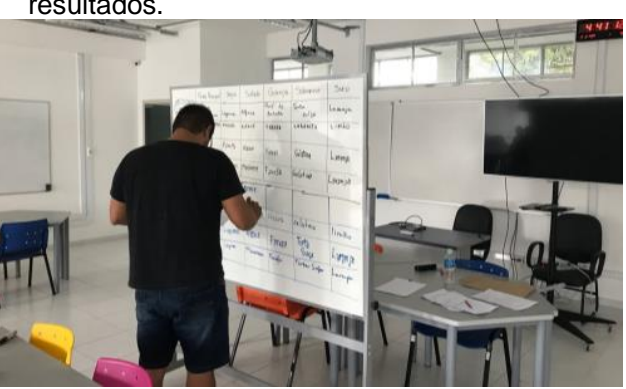

$2^{\text {a }}$ Rodada - Os grupos são refeitos, de modo que, cada grupo tenha pelos menos um integrante dos grupos iniciais (1 $\stackrel{\text { a }}{\text { Rodada). }}$

Os novos grupos apresentam seu cardápio, o qual foi elaborado com todas as informações disponíveis. Há discussão dos resultados.

Fonte: Autores (2018).

Nessa etapa da dinâmica os grupos e o docente devem discutir sobre os resultados alcançados, visando relacionar a Dinâmica da Cozinha com a estrutura 
organizacional de uma empresa e como as decisões são tomadas. Para isso, as seguintes questões podem ser discutidas:

- Qual a relação do processo de definição do cardápio com a realidade organizacional?

- Como avaliar o processo de definição de critérios para tomada de decisão?

- Qual a relação do trabalho em grupo com a Engenharia Simultânea?

- Como o grupo interpreta ótimo parcial versus ótimo global?

No final dessa etapa pode-se:

1. Solicitar um feedback dos alunos - segundo Hwang e Chang (2011) é importante um feedback rápido para uma melhor reflexão, análise crítica e identificação de pontos de melhoria (vide as três questões norteadoras no item 4);

2. Escolher o melhor cardápio - Os participantes devem decidir qual dos cardápios escolheria para degustar.

\section{PROCEDIMENTO DE PESQUISA}

A revisão teórica foi baseada em artigos obtidos na base Web of Science, usando com palavras-chave Engineer Skill e Engineer Education nas categorias de Education Scientific Disciplines, Multidisciplinary Engineering e Educational Research.

A pesquisa foi conduzida em 4 (quatro) turmas da disciplina Gestão da Produção, na qual dois docentes ministraram a dinâmica em uma amostra de 102 graduandos dos cursos de Engenharia Mecânica Diurno e Noturno das turmas de 2017-2018.

Esta pesquisa possui enfoque qualitativo, com as seguintes características: a fonte de dados é o ambiente natural; a pesquisa é descritiva; o interesse do investigador é maior pelo processo do que pelo produto (resultados); a análise dos dados tende a ocorrer de forma indutiva; o significado dos julgamentos é de fundamental importância para a pesquisa (MIGUEL, 2012).

A coleta de dados consistiu no registro escrito sem identificação dos estudantes respondentes. Foi apresentada uma pergunta de cada vez e após sua respectiva resposta escrita foi recolhida. As questões norteadoras na respectiva ordem de aplicação foram:

- O que aprendi com essa dinâmica? 
- Quais os pontos positivos da dinâmica?

- Quais as melhorias que podem ser aplicadas à essa dinâmica ou quais os pontos negativos da dinâmica?

Ao final, as respostas consolidadas de cada turma foram discutidas com os estudantes em sala de aula. Após essa etapa os docentes da disciplina discutiram entre si as respostas.

\section{RESULTADOS}

No Quadro 3 estão registradas as respostas relativas a que os estudantes aprenderam com a dinâmica, conforme descrito no item 4. Na parte inferior do quadro estão algumas das repostas apresentadas pelos alunos. Os docentes concentraram as respostas dos alunos em três respostas principais, conforme apresentado na parte superior do quadro.

Quadro 3 - Respostas para: O que Aprendi hoje?

\begin{tabular}{|c|c|c|c|c|c|}
\hline & O que aprendi hoje? & Turma1 & Turma2 & Total & $\%$ \\
\hline 1 & Critérios para tomada de decisões. & 21 & 10 & 31 & 30,39 \\
\hline 2 & Trabalho em equipe multidisciplinar e compartilhamento de informações. & 15 & 15 & 30 & 29,41 \\
\hline 3 & Analisar todos os fatores que influenciam o problema (Visão Global). & 23 & 18 & 41 & 40,20 \\
\hline \multicolumn{6}{|c|}{ Algumas respostas dos estudantes, as quais foram concentradas em um dos itens acima } \\
\hline & $\begin{array}{l}\text { Importância de cada área no produto final. } \\
\text { Ninguém se importa com harmonização dos pratos. } \\
\text { Apesar dos dados serem os mesmos os cardápios não foram. } \\
\text { Para obter bons resultados deve-se levar em conta vários fatores. } \\
\text { Setores diferentes são importantes. } \\
\text { Trabalho em equipe multidisciplinar traz melhores resultados. } \\
\text { Visão global. } \\
\text { Compartilhar informações. } \\
\text { Organização de ideias. } \\
\text { Escolha depende dos critérios e/ou parâmetros adotados. } \\
\text { Critérios para tomada de decisão. } \\
\text { Não existe "uma melhor" decisão. } \\
\text { O sucesso de uma empresa depende do bom relacionamento entre as áreas. } \\
\text { Todas as áreas da empresa são importantes. } \\
\text { Trabalhar com critérios quantitativos e qualitativos para tomada de decisão. } \\
\text { Cada um defende seu interesse. }\end{array}$ & & & & \\
\hline
\end{tabular}

Fonte: Autores (2018).

Essas três respostas indicam que $40 \%$ dos alunos entenderam que para resolver um problema da melhor maneira possível é necessário ter uma visão global do mesmo; $30 \%$ dos alunos responderam ser necessário algum critério para tomadas de decisões e $30 \%$ dos alunos reconhecem a necessidade do trabalho em equipe para solucionar problemas.

O Quadro 4 apresenta as respostas relativas aos pontos positivos da Dinâmica. Na parte inferior do quadro estão algumas das repostas apresentadas pelos alunos. 
Os professores concentraram todas as respostas dos alunos em três repostas principais, conforme apresentado na parte superior do quadro.

Quadro 4 - Respostas para: Quais os pontos positivos da Dinâmica da Cozinha

\begin{tabular}{|c|c|c|c|c|c|}
\hline & Quais os pontos positivos & Turma1 & Turma2 & Total & $\%$ \\
\hline 1 & $\begin{array}{l}\text { Trabalho em equipe - Equipes multifuncionais - Vários pontos de vista - } \\
\text { Compartilhamento de informações/conhecimento. }\end{array}$ & 18 & 22 & 40 & 37,74 \\
\hline 2 & Prática e teoria - sair da rotina - desenvolver argumentação. & 17 & 14 & 31 & 29,25 \\
\hline 3 & Estimular o senso crítico - Discutir critérios - Tomada de decisão. & 20 & 15 & 35 & 33,02 \\
\hline \multicolumn{6}{|c|}{ Algumas respostas dos estudantes, as quais foram concentradas em um dos itens acima. } \\
\hline \multicolumn{6}{|c|}{$\begin{array}{l}\text { Desenvolver comunicação, trabalho em grupo e pensamento crítico. } \\
\text { Ouvir, opinar e propor soluções. } \\
\text { Promover a discussão e o aprendizado através de problemas reais. } \\
\text { Entender que uma tomada de decisão envolve multicritérios. } \\
\text { Compartilhar informações para tomada de decisão. } \\
\text { Interação com o grupo. } \\
\text { Surpresa ao ver que os grupos tinham critérios diferentes. } \\
\text { Troca dos integrantes entre os grupos para discutir outros critérios. } \\
\text { Aprender com a "competição" faz o aprendizado ser melhor. } \\
\text { É bacana se envolver com uma situação atípica de sala de aula. } \\
\text { Trabalhar com prática e teoria. }\end{array}$} \\
\hline
\end{tabular}

Fonte: Autores (2018)

Essa três respostas indicam que 38\% dos alunos entenderam que o trabalho em equipe e, consequentemente, a troca de informações foram os pontos positivos da dinâmica; 33\% dos alunos acharam que estimular o senso crítico e discutir critérios para tomada de decisão foi o que tornou a dinâmica interessante; e 29\% entenderam como ponto forte da dinâmica, que a aula saiu da rotina e uniu a teoria com a prática, forçando os participantes argumentarem sobre seus pontos de vista.

No Quadro 5, na parte inferior, são apresentadas as respostas dos alunos e, na parte superior, os professores concentraram todas as respostas dos alunos em três repostas principais com relação ao questionamento: Quais as melhorias que podem ser aplicadas à Dinâmica da Cozinha? Ou quais os pontos negativos da Dinâmica da Cozinha?

Quadro 5 - Respostas para: Quais as melhorias que podem ser aplicadas à Dinâmica da Cozinha? 


\begin{tabular}{|c|c|c|c|c|c|}
\hline & Pontos negativos & Turma1 & Turma2 & Total & $\%$ \\
\hline 1 & $\begin{array}{l}\text { Melhorar/atualizar dados/enunciado/objetivo/processo da dinâmica - Incluir restrições } \\
\text { como a calorias. }\end{array}$ & 25 & 24 & 49 & 59,04 \\
\hline 3 & Apresentar dados e/ou ferramentas para tomada de decisões & 12 & 7 & 19 & 22,89 \\
\hline 4 & Tempo insuficiente & 5 & 10 & 15 & 18,07 \\
\hline \multicolumn{6}{|c|}{ Algumas respostas dos estudantes, as quais foram concentradas em um dos itens acima } \\
\hline & $\begin{array}{l}\text { Tá legal. } \\
\text { Faltaram restrições para custo, tempo e aceitação. } \\
\text { Mostrar a foto dos pratos (alguns pratos desconhecidos). } \\
\text { Usar mais cálculos para decidir o cardápio. } \\
\text { Mais informações para melhorar a forma de decisão. } \\
\text { Ter mais informações antes do processo, ou seja, fariamos sabendo o que estávamos } \\
\text { Usar o Excel para fazer avaliações quantitativas. } \\
\text { A escolha do prato pode ser estatística ou quantitativamente. } \\
\text { Mais tempo para discussão final. } \\
\text { Mais tempo para escolha do cardápio. } \\
\text { Dados mais concretos. } \\
\text { Atualizar os dados. Deixar claro que os dados são confiáveis e é necessário trabalhar } \\
\text { Escolher qual grupo foi melhor. } \\
\text { Manter em segredo os critérios e misturar os grupos antes de revelá-los. } \\
\text { Fazer comparação ente os cardápios inicial e final. } \\
\text { Explicar que se trata de uma dinâmica e o objetivo dela. Muito não entenderam no inici } \\
\text { Mais informações iniciais. } \\
\text { Ter esse tipo de atividade com mais frequência. }\end{array}$ & buscando & o. & idos. & \\
\hline
\end{tabular}

Fonte: Autores (2018)

Para 59\% dos alunos deveriam ser feitas mudanças com relação ao texto da dinâmica e, principalmente, a inclusão de restrições ou critérios para custo, tempo de preparo e aceitação dos pratos, similar ao que foi apresentado para o item calorias. Os autores acreditam que quanto mais restrições ou critérios explícitos forem fornecidos, menor a possibilidade de discussão na busca de consenso, como acontece no mundo real, onde as soluções não estão prontas. Espera-se que ao fornecer restrições de orçamento para o preço do cardápio a decisão fique voltada para escolha dos pratos mais baratos. Da mesma maneira para o item satisfação do cliente que a escolha busque pratos que atendam melhor ao gosto do cliente, e que $o$ item tempo de preparação e dificuldade provoque uma tendência de escolha para os pratos mais rápidos e fáceis de preparo.

Os estudantes indicam que seriam beneficiados por uma orientação prévia de apresentação de dados e ferramentas de tomada de decisão (23\%). Os docentes observam que isto comprometeria o estímulo à busca de soluções originais.

Para $18 \%$ dos alunos deveria haver mais discussão ou interação entre os grupos e um tempo maior para executar a Dinâmica da Cozinha.

\section{CONCLUSÕES}


O aprendizado, de certa forma, é uma "re"construção do conhecimento pelo estudante. Durante esse processo, além de apreender os conteúdos, objeto de seu esforço de aprendizagem, se estabelecem relacionamentos e lógicas que the são exclusivas. Aprender envolve a construção do conhecimento, exigindo que o aprendiz procure, ativamente, criar significado para suas próprias experiências pela relação de novas informações com o que ele já sabe.

Os resultados dessas pesquisas evidenciaram que a Dinâmica da Cozinha estimulou a participação dos estudantes, a reflexão e discussão crítica em sala de aula, a motivação para o auto aprendizado dos conteúdos trabalhados, como por exemplo, técnicas de tomada de decisão e negociação e trabalhos em equipes multidisciplinares.

Ainda que a dinâmica possa estimular o interesse pelos temas Gestão de Produto, Quality Function Deployment (QFD) recomenda-se que o docente indique leitura de artigos para fundamentar debate qualificado e participação coletiva.

Educadores têm a responsabilidade de ajudar os estudantes a navegarem por situações de dificuldade e negociarem as consequências de seus atos, permitindo ainda examinar e refletir sobre decisões tomadas. Os estudantes engajados na dinâmica vivenciaram tal experiência. Os resultados desta pesquisa indicam que, além de melhorar o aprendizado do estudante, há melhora no seu engajamento para o ato de aprender.

Como trabalho futuro, sugere-se avaliar o Método usando o procedimento indicado por Mohan et al. (2009) em disciplinas de outros cursos de Engenharia numa amostra mais ampla de cursos e participantes.

\section{AGRADECIMENTOS}

Registra-se a co-autoria do Prof. Dr. Paulo T. M Lourenção na elaboração da Dinâmica da Cozinha.

\section{REFERÊNCIAS}


BRINT, S.; CANTWELL, A. M.; HANNEMAN, R. A.The two cultures of undergraduate academic engagement. Research in Higher Education, v. 49, p. 383-403, 2008.

https://doi.org/10.1007/s11162-008-9090-y

DYM, C. L. Design, Systems, and Engineering Education. International Journal of Engineering Education, v. 20, n.3, p. 305-312, 2004.

ELLIS, R. A.; GOODYEAR, P.; CALVO, R. A.; PROSSER, M. Engineering students' conceptions of and approaches to learning through discussions in face-to-face and online contexts. Learning and Instructions, v. 18, p. 267-282, 2008. https://doi.org/10.1016/j.learninstruc.2007.06.001

ENADE, 2017. Provas e gabritos. Disponível em: http://portal.inep.gov.br/web/guest/provas-egabaritos3. Acesso em 30 set. 2018.

GUIMARÃES, E. M. P.; ÉVORA, Y. D. M. Sistema de informação: instrumento para tomada de decisão no exercício da gerência. Ci. Inf., Brasília, v. 33, n. 1, p. 72-80, jan./abr. 2004. Disponível em: http://www.scielo.br/pdf/ci/v33n1/v33n1a09. Acesso em: 30 set. 2018. https://doi.org/10.1590/S0100-19652004000100009

HWANG, G.; CHANG, H.A Formative Assessment-Based Mobile Learning Approach to Improving the Learning Atitudes and Achivements of Students. Computer and Education, v. 56, p. 1023-1031, 2011.https://doi.org/10.1016/j.compedu.2010.12.002

JACKSON, L.; MEYER, W.; PARKINSON, J. A Study of the Writing Tasks and Reading Assigned to Undergraduate Science Students at a South African University. English for Specific

Purposes, v. 25, p. 260-281, 2006. https://doi.org/10.1016/j.esp.2005.04.003

KEMBER, D., LEUNG, D. P., McNAUGHT, C. A Workshop Activity to Demonstrate that Approaches to Learning are Influenced by the Teaching and Learning Environment. Active Learning in Higher Education, v. 9, n. 1, p.43-56, 2008.

https://doi.org/10.1177/1469787407086745

LANG, J. D., CRUSE, S., McVEY, F. D., McMASTERS, J. Industry Expectations of New Engineers: A Survey to Assist Curriculum Designers. Journal of Engineering Education, v. 88, n. 1, p. 43-51,1999. https://doi.org/10.1002/j.2168-9830.1999.tb00410.x

LIMA, B.P.; MUNIZ JUNIOR, J.; FORTI, A.W. Projeto de embalagens para peças de automotivas aplicando o desdobramento da função qualidade (QFD). Revista Gestão Industrial, v. 8, n. 3, p. 126-141, 2012. Disponível em: https://periodicos.utfpr.edu.br/revistagi/article/view/1058/870. Acesso em: 30 set. 2018. https://doi.org/10.3895/S1808-04482012000300006

LUJAN, H. L.; DiCARLO, S. E. Too Much Teaching, not enough Learning: what is the soluction? Advances in Psychology Education, v. 30, p. 17-22, 2006.

https://doi.org/10.1152/advan.00061.2005

MARCH, E.; GAFFNEY, J. S. Relational Identities of Students, Families, and Educators.

Remedial and Special Education, v. 31, n. 1, p. 3-16, 2010.

https://doi.org/10.1177/0741932508324393

MARTIN, R.; MAYTHAM, B.; CASE, J.; FRASER, D. Engineering graduates' perceptions of how well they were prepared for work in industry. European Journal of Engineering Education, $v$. 30, n. 2, p.167-180, 2005. https://doi.org/10.1080/03043790500087571

MESQUITA, D., LIMA, R. M.; PEREIRA, G. Engenharia e Gestão Industrial em Portugal: Uma Visão da Procura Profissional. In: CONGRESSO LUSO-MOÇAMBICANO DE ENGENHARIA (CLME'2008), 5., 2008. Moçambique: Maputo, [Anais...] Moçambique: Maputo, 2008. 
MINISTÉRIO DA EDUCAÇÃO E CULTURA (MEC), Conselho Nacional de Educação - Câmara de Educação Superior. Resolução CNE/CES 11, de 11 de Março de 2002. Brasília, 2002.

Disponível em:

http://portal. mec.gov.br/index.php?option=com docman\&view=download\&alias=15766-rces01102\&category slug=junho-2014-pdf\&ltemid=30192.

MIGUEL, P. A. C. (Org) Metodologia de pesquisa em engenharia de produção e gestão de operações. 2. Ed. São Paulo: Campus, 2012.

MOHAN, A; MERLE, D.; JACKSON, C.; LANNIN, J. NAIR, S.S. Professional Skills in the Engineering Curriculum. IEEE Transactions on Education, v. 53, n. 4, p. 562-571, 2009. https://doi.org/10.1109/TE.2009.2033041

MONTERO, E.; GONZÁLEZ, M. J. Student Engagement in a Structured Problem-Based Approach to Learning: A First-Year Eletronic Engineering Study Module on Heat Transfer. IEEE Transaction on Education, v. 52, n. 2, p. 214-221, 2009.

https://doi.org/10.1109/TE.2008.924219

MUNIZ Jr., J. Gestão de Projetos e Engenharia Simultânea. Video Aula UNIVESP. Disponível em: https://www.youtube.com/watch?v=Stgyry24 kE. Acessado em: 30/09/2018.

https://doi.org/10.1590/0104-530x1172-15

MUNIZ Jr., J.; DELAMARO, M. C.; SALOMON, SALOMON, V. A. P.; CARVALHO, R.; FREIRE Jr., J. C, HATAKEYAMA, K.; SAMED, M. M. A. Reflexões sobre evasão e a retenção principalmente nas primeiras séries dos cursos de engenharia de produção. In: Oliveira, V. F.; Cavenaghi, V.; Másculo F. S.. (Org.). Tópicos Emergente e desafios metodológicos em Engenharia de Produção: casos, experiências e proposições. Rio de Janeiro: ABEPRO v. 2, p. 79-87, 2009.

MUNIZ JR., J. RODRIGUES, J. S.; ASSIS, A.; OLIVEIRA, F. C. P.; FRANCO, B. C.; MACIEL, F. G. Increasing students' skills in operations management classes: Cumbuca Method as teachinglearning strategy. Gestão da Produção, São Carlos, v. 24, n. 4, p. 680-689, Dec. 2017.

Disponível em: http://www.scielo.br/scielo.php?script=sci arttext\&pid=S0104-

530X2017000400680\&lng=en\&nrm=iso. Acesso em: 30 set. 2018.

PALMER, S.; HOLT, D.; BRAY, S. Does the Discussion Help? The Impact of a Formally Assessed Online Discussion on Final Student Results. British Journal of Educational Technology, v. 39, n. 5, p. 847-858, 2008. https://doi.org/10.1111/j.1467-8535.2007.00780.x

SAVANDER-RANNE, C.; LUNDÉN, O.; KOLARI, S. An alternative teaching method for electrical engineering courses. IEEE Transactions on Education, v. 51, n. 4, p. 423-431, 2008.

$<$ https://ieeexplore.ieee.org/document/4475815>. Acesso em 30 set. 2018.

https://doi.org/10.1109/TE.2007.912500

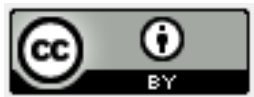

Artigo recebido em:28/10/2018 e aceito para publicação em: 01/12/2019 DOI: http://dx.doi.org/10.14488/1676-1901.v19i4.3422 


\section{APÊNDICE 1}

A Dinâmica da Cozinha consiste, basicamente, em preparar um cardápio de 5600 refeições contendo um prato principal, uma sopa, uma salada, uma guarnição, uma sobremesa e um suco. A dinâmica pode ser dividida em duas etapas, as quais são descritas a seguir.

\section{Primeira Etapa:}

1. Os participantes da Dinâmica da Cozinha devem ser divididos em 4 (quatro) grupos, um grupo para cada conjunto de informações relacionadas a elaboração do cardápio, conforme será apresentado no item 2. Cada grupo deve ter no mínimo 4 participantes. Evitar grupo como muitos participantes, uma vez que podem gerar conversas paralelas, as quais prejudicam a Dinâmica.

2. Cada grupo recebe apenas um conjunto de informações específicas para propor um cardápio, as quais estão relacionadas a um setor ou departamento organizacional específico:

a. Grupo A (Engenharia) - conjunto de informações referentes as calorias dos pratos (Apêndice 2 - Tabela 1). Deverão propor um cardápio que tenha em média 1400 calorias/refeição;

b. Grupo B (Qualidade) - conjunto de informações referentes a preferência do cliente (Apêndice 3 - Tabela 2). Deverão propor um cardápio analisando o índice de aceitação de cada item disponível;

c. Grupo D (Produção) - conjunto de informações referentes a dificuldade de preparação dos pratos (Fácil, Médio, Difícil) e tempo de preparação de cada refeição (Apêndice 4 - Tabela 3). Deverão propor um cardápio analisando essas informações;

d. Grupo C (Finanças) - conjunto de informações referentes aos custos de cada item do cardápio (Apêndice 5 - Tabela 4) e indica-se que há restrições de orçamento para fornecer as 5600 refeições.

3. Cada grupo dispõe de informações exclusivas e desconhece o conjunto de informações dos demais grupos. Orientar os alunos que se trata de uma competição e os grupos não devem se comunicar; 
4. Finalizada a elaboração do cardápio cada grupo deve registrar seu cardápio na lousa para que todos possam analisar os cardápios propostos, conforme Quadro 1;

Quadro 1 - Cardápio escolhido por cada grupo

\begin{tabular}{|l|l|l|l|l|}
\hline \multirow{2}{*}{ Prato Principal } & \multicolumn{4}{c|}{ Grupo } \\
\cline { 2 - 5 } & A & B & C & D \\
\hline Sopa & & & & \\
\hline Salada & & & & \\
\hline Guarnição & & & & \\
\hline Sobremesa & & & & \\
\hline Suco & & & & \\
\hline
\end{tabular}

Fonte: Autores (2018).

5. Cada grupo escolhe um representante, o qual, individualmente, irá discorrer sobre os critérios adotados para escolha do seu cardápio, além do que, sobre o conjunto de informações fornecidas ao seu grupo. Enquanto isso, os demais grupos observam e preparam críticas para o cardápio apresentado. Em seguida, o representante ouve as críticas separadamente por grupo e, com a ajuda dos demais integrantes do seu grupo, as rebate. O moderador (professor) faz um balanço das críticas e repostas para registro. Esse item é finalizado quando todos os grupos apresentarem seus cardápios e forem questionados.

6. O moderador faz um balanço final dessa primeira rodada orientado por algumas perguntas pertinentes, tais como:

a. Qual o melhor cardápio?

b. O grupo se orientou por qual parâmetro/informação?

c. O grupo trabalhou com algum parâmetro diferente do fornecido? Como isso foi possível sem dados a respeito dele?

OBS: Algumas escolhas do cardápio podem ser feitas pelo gosto dos integrantes do grupo (satisfação do cliente), mesmo eles não tendo informação específica a respeito disso.

d. Quais as dificuldades na hora da escolha?

e. Há semelhanças com o dia-a-dia do trabalho? Quais? 
f. Podemos fazer a seguinte relação:

$$
\begin{aligned}
& \text { Nutrição = Engenharia. } \\
& \text { Satisfação = Qualidade. } \\
& \text { Custos = Finanças. } \\
& \text { Tempo e Dificuldade = Produção/Processo. }
\end{aligned}
$$

g. Qual seria uma alternativa de trabalho?

\section{Segunda Etapa:}

1. Reorganizar os grupos, de modo que tenham pelo menos um integrante de cada conjunto de informações. Assim sendo, cada grupo terá disponível todas as informações e restrições referentes a cada item do cardápio (calorias, custos, tempo e grau de dificuldade, aceitação/satisfação).

2. Elaborar um novo cardápio (repetir os itens 3 e 4 da primeira etapa).

3. O moderador faz um balanço final dessa segunda etapa discutindo com os grupos:

a. Quais foram os critérios adotados para a elaboração do cardápio na nessa etapa?

b. Qual das informações específicas apresentadas (Calorias, Custos, Tempo/Grau de dificuldade, Satisfação) você considera a mais relevante? Por quê?

c. O que chamou a atenção neste trabalho?

d. Como foi ponderada a importância de cada critério? (igual ou diferente e por quê)

4. Escolher um cardápio vencedor. Os participantes devem votar pensando qual cardápio escolheriam baseados em seus gostos pessoais. 


\section{APÊNDICE 2}

Tabela 1 - Calorias dos itens disponíveis para elaboração do cardápio.

\begin{tabular}{|c|c|c|c|}
\hline PRATO & CALORIAS & & CALORIAS \\
\hline Principal & & Salada & \\
\hline Bovina & & Abobrinha & 61 \\
\hline Bife Grelhado & 307 & Maionese & 227 \\
\hline Bife Role & 272 & Alface & 16 \\
\hline Bife a Parmegiana & 781 & Tomate/Cebola & 98 \\
\hline Suína & & Húngara & 186 \\
\hline Bisteca & 243 & Guarnição & \\
\hline Lombo & 424 & Purê de batata & 145 \\
\hline Pernil Assado & 524 & Polenta & 184 \\
\hline Aves & & Espaguete & 264 \\
\hline Frango Assado & 534 & Farofa & 279 \\
\hline Frango Grelhado & 303 & Cuscuz & 391 \\
\hline Frango ao Molho & 524 & Couve a mineira & 62 \\
\hline Peixe & & Sobremesas & \\
\hline Filé a Dore & 428 & Gelatina & 167 \\
\hline Postas Assada & 299 & Rocambole & 178 \\
\hline Embutidos & & Bolos & 137 \\
\hline Salsicha & 257 & Torta Suiça & 227 \\
\hline Lingüiça & 443 & Laranja & 126 \\
\hline \multirow[t]{2}{*}{ Hambúrguer a Parmegiana } & 980 & Sucos & \\
\hline & & Caju & 96 \\
\hline \multirow[t]{2}{*}{ Feijoada } & 992 & Abacaxi & 96 \\
\hline & & Groselha & 96 \\
\hline SOPAS & & Limão & 96 \\
\hline Palmito & 131 & Laranja & 96 \\
\hline Cremosa & 131 & Leite & 96 \\
\hline Legumes & 131 & Guaraná & 96 \\
\hline Massas & 131 & & \\
\hline Prontas & 131 & & \\
\hline
\end{tabular}

Fonte: Autores (2018). 


\section{APÊNDICE 3}

Tabela 2 - Índice de aceitação dos itens disponíveis para elaboração do cardápio.

\begin{tabular}{|c|c|c|c|}
\hline PRATO & \% ACEITAÇÃ O & (2) & \% ACEITAÇÃ̃O \\
\hline Principal & & Salada & \\
\hline Bovina & & Abobrinha & 50 \\
\hline Bife Grelhado & 94 & Maionese & 81 \\
\hline Bife Role & 68 & Alface & 81 \\
\hline Bife a Parmegiana & 81 & Tomate/Cebola & 81 \\
\hline Suína & & Húngara & 56 \\
\hline Bisteca & 69 & Guarnição & \\
\hline Lombo & 69 & Purê de batata & 62 \\
\hline Pernil Assado & 63 & Polenta & 25 \\
\hline Aves & & Espaguete & 50 \\
\hline Frango Assado & 69 & Farofa & 69 \\
\hline Frango Grelhado & 75 & Cuscuz & 50 \\
\hline Frango ao Molho & 38 & Couve a mineira & 81 \\
\hline Peixe & & Sobremesas & \\
\hline Filé a Dore & 69 & Gelatina & 63 \\
\hline Postas Assada & 56 & Rocambole & 44 \\
\hline Embutidos & & Bolos & 44 \\
\hline Salsicha & 31 & Torta Suíça & 56 \\
\hline Lingüiça & 31 & Laranja & 38 \\
\hline \multirow[t]{2}{*}{ Hambúrguer a Parmegiana } & 50 & Sucos & \\
\hline & & Caju & 50 \\
\hline \multirow[t]{2}{*}{ Feijoada } & 81 & Abacaxi & 44 \\
\hline & & Groselha & 13 \\
\hline SOPAS & & Limão & 69 \\
\hline Palmito & 94 & Laranja & 75 \\
\hline Cremosa & 81 & Leite & 50 \\
\hline Legumes & 87 & Guaraná & 50 \\
\hline Massas & 56 & & \\
\hline Prontas & 37 & & \\
\hline
\end{tabular}

Fonte: Autores (2018). 


\section{APÊNDICE 4}

Tabela 3 - Tempo de preparo e grau de dificuldade dos itens disponíveis para elaboração do cardápio.

\begin{tabular}{|c|c|c|c|c|c|}
\hline PRATO & Preparo (hs) & Dificuldade & & Preparo (hs) & Dificuldade \\
\hline Principal & & & Salada & & \\
\hline Bovina & & & Abobrinha & 4 & $\mathrm{~F}$ \\
\hline Bife Grelhado & 5 & $\mathrm{~F}$ & Maionese & 5 & M \\
\hline Bife Role & 7 & $\mathrm{D}$ & Alface & 3 & $\mathrm{~F}$ \\
\hline Bife a Parmegiana & 10 & $\mathrm{D}$ & Tomate/Cebola & 4 & $\mathrm{~F}$ \\
\hline Suína & & & Húngara & 4 & $\mathrm{M}$ \\
\hline Bisteca & 7 & $\mathrm{M}$ & Guarnição & & \\
\hline Lombo & 6 & $\mathrm{M}$ & Purê de batata & 5 & $\mathrm{~F}$ \\
\hline Pernil Assado & 3 & $\mathrm{M}$ & Polenta & 4 & $\mathrm{~F}$ \\
\hline Aves & & & Espaguete & 3 & $\mathrm{~F}$ \\
\hline Frango Assado & 13 & $\mathrm{D}$ & Farofa & 4 & $\mathrm{~F}$ \\
\hline Frango Grelhado & 5 & $\mathrm{D}$ & Cuscuz & 4 & $\mathrm{~F}$ \\
\hline Frango ao Molho & 7 & $\mathrm{M}$ & Couve a mineira & 5 & $\mathrm{~F}$ \\
\hline Peixe & & & Sobremesas & & \\
\hline Filé a Dore & 5 & $\mathrm{D}$ & Gelatina & 9 & $\mathrm{~F}$ \\
\hline Postas Assada & 5 & $\mathrm{M}$ & Rocambole & 9 & $\mathrm{M}$ \\
\hline Embutidos & & & Bolos & 10 & $\mathrm{M}$ \\
\hline Salsicha & 1 & $\mathrm{~F}$ & Torta Suíça & 8 & $\mathrm{M}$ \\
\hline Lingüiça & 3 & $\mathrm{~F}$ & Laranja & 1 & $\mathrm{~F}$ \\
\hline \multirow[t]{2}{*}{ Hambúrguer a Parmegiana } & 6 & $\mathrm{M}$ & Sucos & & \\
\hline & & & Caju & 2 & $\mathrm{~F}$ \\
\hline \multirow[t]{2}{*}{ Feijoada } & 6 & $\mathrm{M}$ & Abacaxi & 2 & $\mathrm{~F}$ \\
\hline & & & Groselha & 2 & $\mathrm{~F}$ \\
\hline SOPAS & & & Limão & 2 & $\mathrm{~F}$ \\
\hline Palmito & 4 & $\mathrm{M}$ & Laranja & 2 & $\mathrm{~F}$ \\
\hline Cremosa & 4 & $\mathrm{M}$ & Leite & 2 & $\mathrm{~F}$ \\
\hline Legumes & 5 & $\mathrm{M}$ & Guaraná & 2 & $\mathrm{~F}$ \\
\hline Massas & 3 & $\mathrm{~F}$ & & & \\
\hline Prontas & 2 & $\mathrm{~F}$ & & & \\
\hline
\end{tabular}

F-Fácil, M-Médio e D-Difícil

Fonte: Autores (2018). 


\section{APÊNDICE 5}

Tabela 4 - Custo para fornecer 5600 de cada item disponível para elaboração do cardápio.

\begin{tabular}{|c|c|c|c|}
\hline PRATO & $\mathbf{R} \$$ & & $\mathbf{R} \$$ \\
\hline Principal & & Salada & \\
\hline Bovina & & Abobrinha & 70,00 \\
\hline Bife Grelhado & 1830,00 & Maionese & 42,00 \\
\hline Bife Role & 2000,00 & Alface & 113,00 \\
\hline Bife a Parmegiana & 2020,00 & Tomate/Cebola & 148,00 \\
\hline Suína & & Húngara & 412,00 \\
\hline Bisteca & 4415,00 & Guarnição & \\
\hline Lombo & 2630,00 & Purê de batata & 255,00 \\
\hline Pernil Assado & 4874,00 & Polenta & 75,00 \\
\hline Aves & & Espaguete & 69,00 \\
\hline Frango Assado & 2902,00 & Farofa & 242,00 \\
\hline Frango Grelhado & 2650,00 & Cuscuz & 167,00 \\
\hline Frango ao Molho & 2534,00 & Couve a mineira & 398,00 \\
\hline Peixe & & Sobremesas & \\
\hline Filé a Dore & 2274,00 & Gelatina & 222,00 \\
\hline Postas Assada & 2004,00 & Rocambole & 212,00 \\
\hline Embutidos & & Bolos & 333,00 \\
\hline Salsicha & 1329,00 & Torta Suíça & 315,00 \\
\hline Lingüiça & 2320,00 & Laranja & 123,00 \\
\hline \multirow[t]{2}{*}{ Hambúrguer a Parmegiana } & 1548,00 & Sucos & \\
\hline & & Caju & 187,00 \\
\hline \multirow[t]{2}{*}{ Feijoada } & 2700,00 & Abacaxi & 158,00 \\
\hline & & Groselha & 158,00 \\
\hline SOPAS & & Limão & 139,00 \\
\hline Palmito & 400,00 & Laranja & 181,00 \\
\hline Cremosa & 117,00 & Leite & 201,00 \\
\hline Legumes & 129,00 & Guaraná & 158,00 \\
\hline Massas & 152,00 & & \\
\hline Prontas & 74,00 & & \\
\hline
\end{tabular}

Fonte: Autores (2018). 